\title{
How payment scheme affects patients' adherence to medications? A systematic review
}

\author{
This article was published in the following Dove Press journal: \\ Patient Preference and Adherence \\ 13 May 2016 \\ Number of times this article has been viewed
}

\author{
Hamiza Aziz',2 \\ Ernieda Hatah' \\ Mohd Makmor Bakry' \\ Farida Islahudin' \\ 'Faculty of Pharmacy, Universiti \\ Kebangsaan Malaysia, Jalan Raja Muda \\ Abdul Aziz, Kuala Lumpur, Malaysia; \\ ${ }^{2}$ Pharmacy Division, Ministry of \\ Health, Jalan Universiti, Petaling Jaya, \\ Malaysia
}

Background: A previous systematic review reported that increase in patients' medication cost-sharing reduced patients' adherence to medication. However, a study among patients with medication subsidies who received medication at no cost found that medication nonadherence was also high. To our knowledge, no study has evaluated the influence of different medication payment schemes on patients' medication adherence.

Objective: This study aims to review research reporting the influence of payment schemes and their association with patients' medication adherence behavior.

Methods: This study was conducted using systematic review of published articles. Relevant published articles were located through three electronic databases Medline, ProQuest Medical Library, and ScienceDirect since inception to February 2015. Included articles were then reviewed and summarized narratively.

Results: Of the total of 2,683 articles located, 21 were included in the final analysis. There were four types of medication payment schemes reported in the included studies: 1) out-of-pocket expenditure or copayments; 2) drug coverage or insurance benefit; 3 ) prescription cap; and 4) medication subsidies. Our review found that patients with "lower self-paying constraint" were more likely to adhere to their medication (adherence rate ranged between $28.5 \%$ and $94.3 \%$ ). Surprisingly, the adherence rate among patients who received medication as fully subsidized was similar (rate between $34 \%$ and $84.6 \%$ ) as that of other payment schemes. The studies that evaluated patients with fully subsidized payment scheme found that the medication adherence was poor among patients with nonsevere illness.

Conclusion: Although medication adherence was improved with the reduction of costsharing such as lower copayment, higher drug coverage, and prescription cap, patients with full-medication subsidies payment scheme (received medication at no cost) were also found to have poor adherence to their medication. Future studies comparing factors that may influence patients' adherence to medication among patients who received medication subsidies should be done to develop strategies to overcome medication nonadherence.

Keywords: medication payment scheme, drug cost, medication adherence

\section{Introduction}

Adherence to medication refers to whether patients take their medications as prescribed and continue taking the prescribed medications. ${ }^{1}$ It involves active, voluntary, and collaborative participation from patients in mutually acceptable course of behavior to produce therapeutic result. ${ }^{2}$ Adherence to medication is important especially in patients with chronic illness to prevent disease-related complication, improve quality of life, and extend life expectancy. Although medication adherence is important, the rate of patients' adherence to medication is somewhat disturbing. According to reports by the World Health Organization, only $50 \%$ of patients with chronic disease adhere to their 
medications. ${ }^{3}$ The situation is reported to be poorer in developing countries due to restricted accessibility to medications and health care services. ${ }^{3,4}$ Poor adherence to medication is reported to be multifactorial. It may be caused by various reasons such as failure to collect or renew the prescription, failure to take medication at the prescribed dosage or interval, and also failure in being persistent or total negligence of medication regimen. ${ }^{5}$ Financial burden such as high cost of medication, medications not covered by insurance, and high out-of-pocket expenses for medication was also reported as a significant barrier to medication adherence. ${ }^{6}$

Patients with chronic illness who need to pay their medication at higher cost (self-paying payment scheme) were more likely to restrict the use of medication. ${ }^{7}$ In a study in the USA, approximately one-quarter of older patients forgo their prescription medications due to the high cost of medication. ${ }^{8}$ Similarly, Zheng et al also reported that patients who paid the cost of medication themselves were more likely to be nonadherent than patients with private insurance. ${ }^{9}$ In their study, high out-of-pocket expenses for medication therapy had negative effect on medication adherence. ${ }^{9}$ Interestingly, the same study reported that patients who received the government subsidies, a different payment scheme, had higher cost-related nonadherence $(\mathrm{CRN})$ rate than patients with private insurance coverage payment scheme. ${ }^{9}$ A similar finding was also reported by Hasalli who conducted a study on returned unused medication at a public hospital in Malaysia. ${ }^{10}$ In his study on patients with government subsidized scheme whose medications were provided as free-of-charge, he found that the returned unused medication was high with an average cost of RM42.35 per patient. One of the reasons perceived for the high rate of returned unused medication was medication nonadherence. It was postulated that the cost of returned unused medication across public hospitals in Malaysia may exceed a few million dollars per year. ${ }^{10}$ The studies discussed earlier show that the types of medication payment schemes may have different impacts on patients' behavior of medication adherence.

Although many studies have evaluated the association of medication cost with nonadherence, it is unknown how medication payment scheme may influence patients' behavior of medication adherence. A previous systematic review of patient cost-sharing and its effect on medication adherence reported that there was a clear relationship between increased costsharing with decrease in medication adherence and patients' health outcomes. ${ }^{11}$ The authors suggested that a reduction of patient cost-sharing in pharmacy bill could increase patients' adherence to their medication and thus reduce unnecessary use of health care resources and total medical costs. ${ }^{11}$ However, as presented earlier, the adherence pattern among patients whose medications were fully subsidized was also reported to be poor. Understanding the relationship between method of payment for medication and its effects on patients' adherence to medication will help exploring the monetary effects on nonadherence. The current study, therefore, aims to 1) explore patients' adherence to medication under different medication payment schemes and 2) to understand potential factors that may influence such results.

\section{Methodology}

This study was conducted using systematic review of previous literature on medication nonadherence under different payment schemes among patients with chronic diseases or chronic conditions. Studies were located through comprehensive literature search of electronic bibliographic databases Medline, ProQuest Medical Library, and ScienceDirect since inception to February 2015. The following subject headings and keywords were used to retrieve the articles: medication adherence, drug cost and health care expenditure, medication concordance, medication fulfillment, cost, value, socioeconomic, medication cost, and medication price. The article search was restricted to English languange, adult and human studies. All articles were imported to EndNote, and duplicate articles were removed from the list.

The retrieved articles were screened using inclusion and exclusion criteria. Articles were included if they evaluated the effect of medication cost or method of payment on patients' medication adherence. The evaluation of medication adherence must be done on adult patients as defined in the original study. Only articles with the following study design were included in the study: randomized controlled trial, cross-sectional, longitudinal, and observational/prospective/ retrospective cohort. Other articles such as review articles, thesis, commentaries, editorial letters, and case studies were excluded. Only articles with clear description of the population involved and methodology were included in the analysis. Study must also report how medication adherence was measured. Articles that involved intervention to improve adherence were excluded from the study.

Initial title/abstracts screening was conducted by HA. During this phase, exclusion of articles only occurred if the reason for exclusion was clear. All excluded full-text articles were reviewed independently by the research team that consisted of three senior lecturers to ensure the validity of the process. Any disagreements on whether a study should be included or excluded were resolved through consensus. 
Primary outcomes were the rate of medication adherence and method of payment for medication. Secondary outcome included other factors (both quantitative and qualitative) that may influence patients' adherence to medication. Included articles were then reviewed and summarized narratively.

\section{Results}

\section{Search results}

A total of 2,683 articles were traced from the three electronic databases. Of these, 85 articles were included for a detailed review of full text. Based on the inclusion and exclusion criteria, a total of 21 articles were included in the final analysis (Figure 1). The summary of articles included is presented in Table 1 . The majority of the study designs were cross-sectional and only one had a controlled or comparison group.

\section{Sample size and participants' characteristics}

Sample size reported in each article varied between 60 and 516,072 . The majority of the studies were conducted in the USA $(n=17)$. Others were in India $(n=1)$, Canada $(n=2)$, and Finland $(\mathrm{n}=1)$. The included studies were conducted on patients with breast cancer, human immunodeficiency virus, chronic myeloid leukemia, diabetes mellitus, end-stage renal disease, depression, chronic pulmonary disease, hypertension, rheumatoid arthritis, schizophrenia, hyperlipidemia, stroke, and overactive bladder.

\section{Appraisal of studies}

The potential bias for the studies was evaluated using the Downs and Black guidelines, ${ }^{12}$ which analyzed 27 items based on the data quality, external and internal validity, and

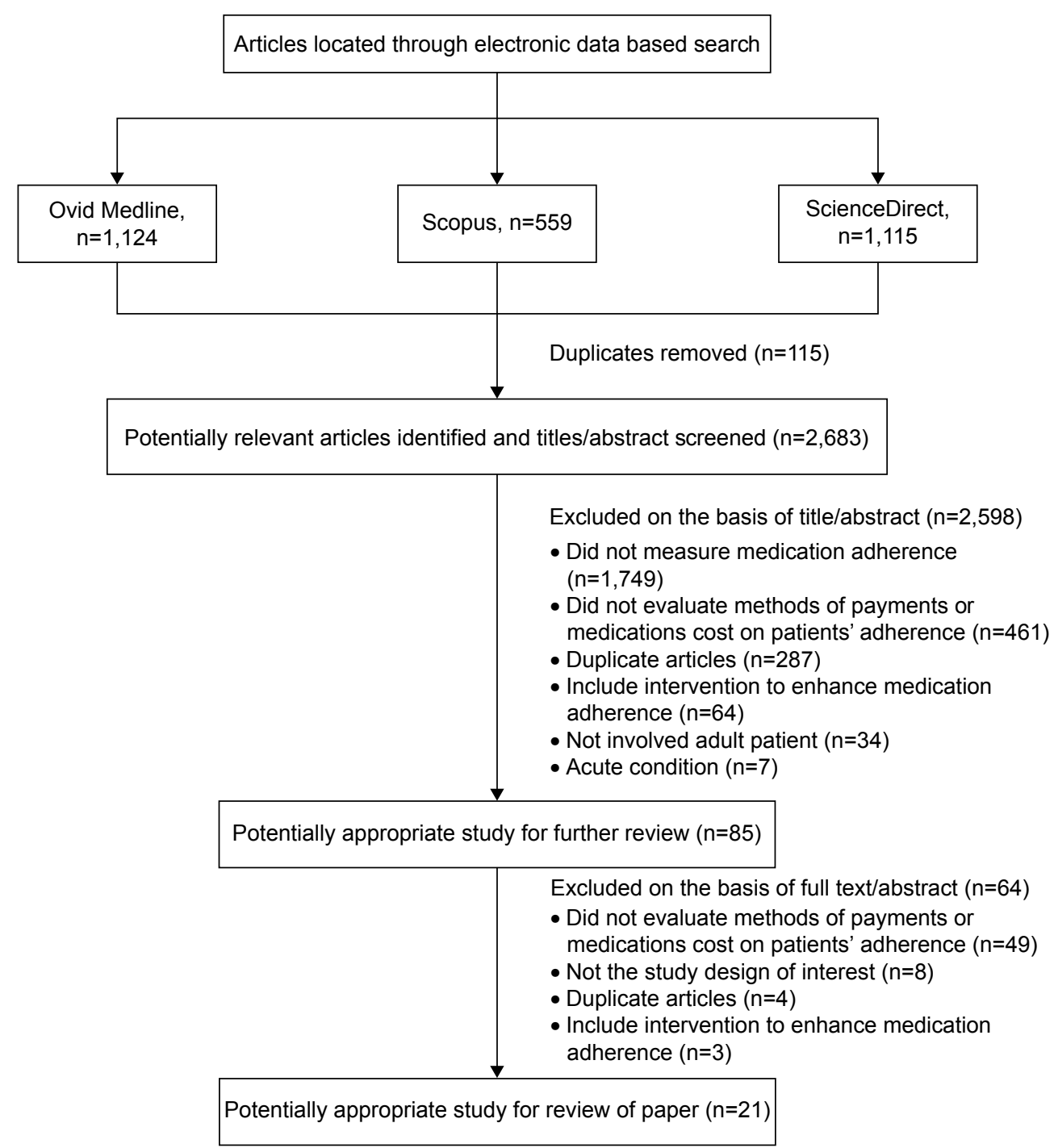

Figure I Systematic review of inclusion and exclusion flowchart. 


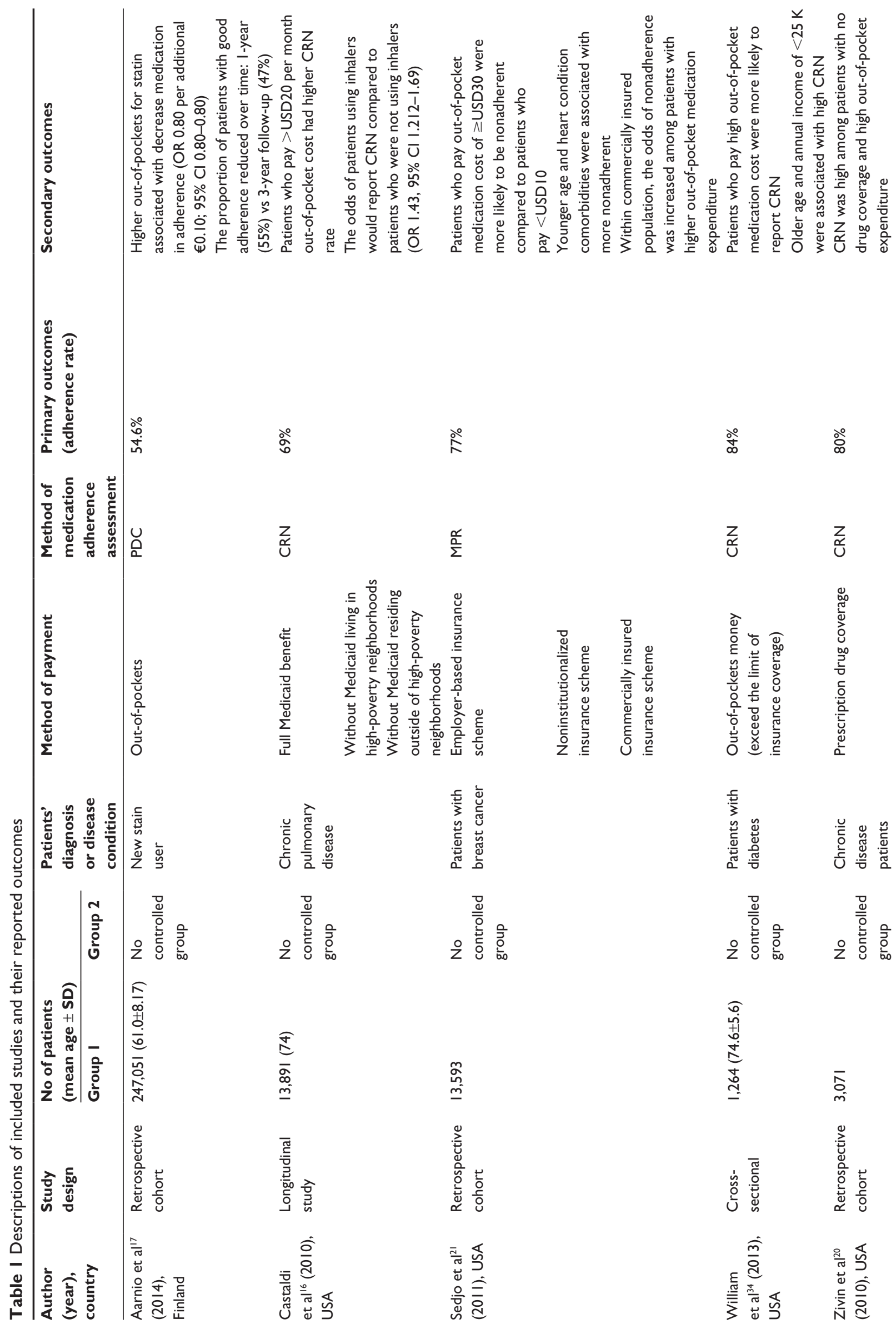




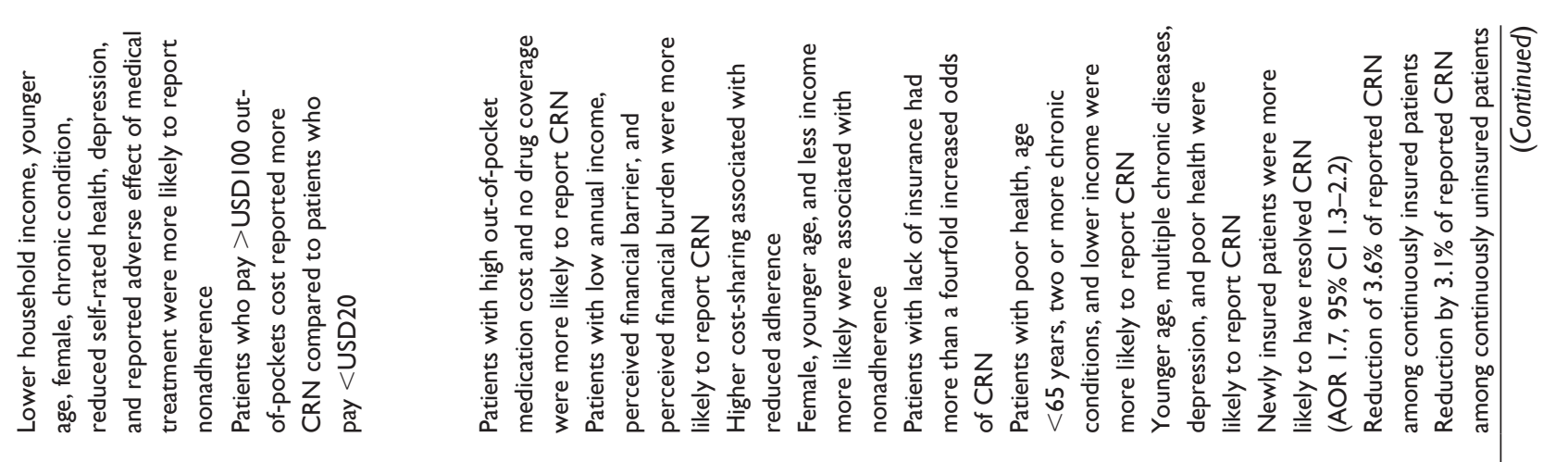

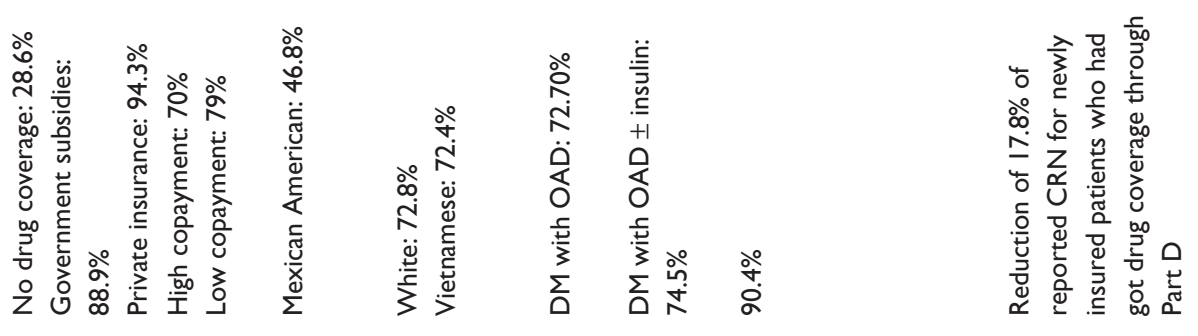

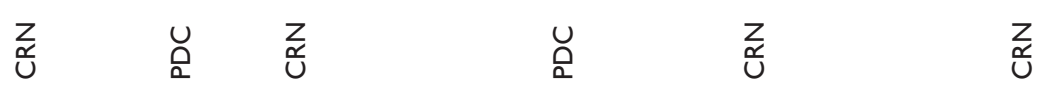

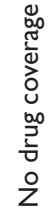

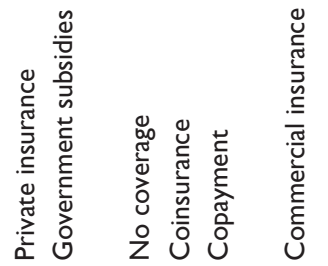

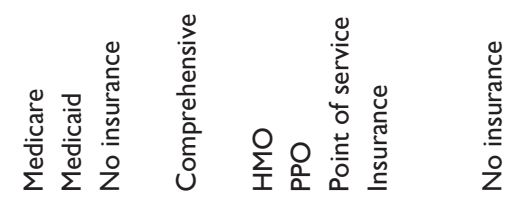

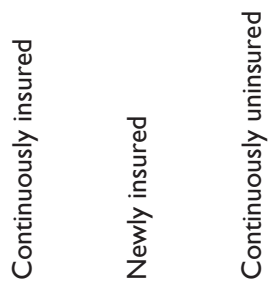

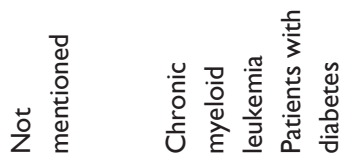

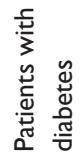

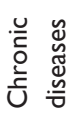

z

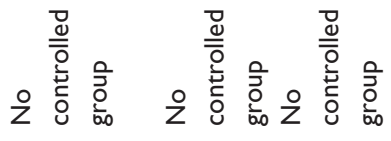

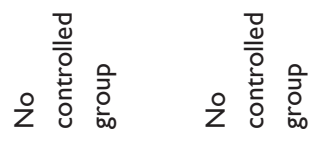

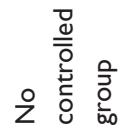

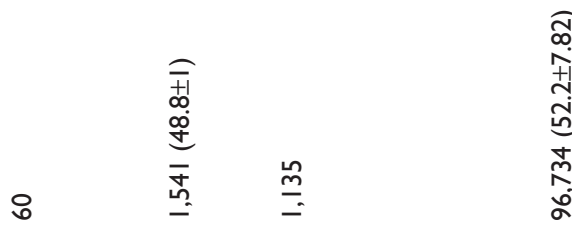

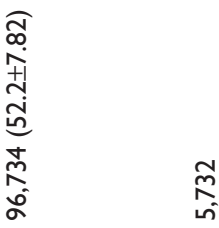

$\underset{\substack{\infty \\ \text { ind }}}{\stackrel{\infty}{\infty}}$

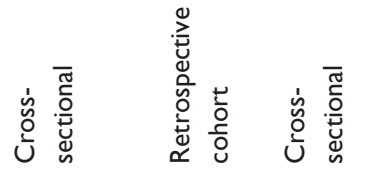

离

离

舀

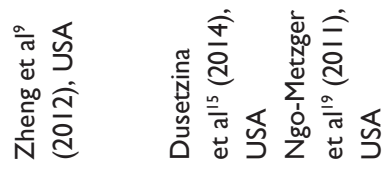

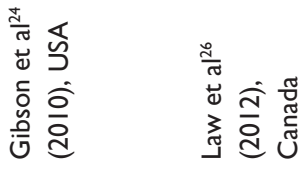

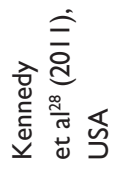




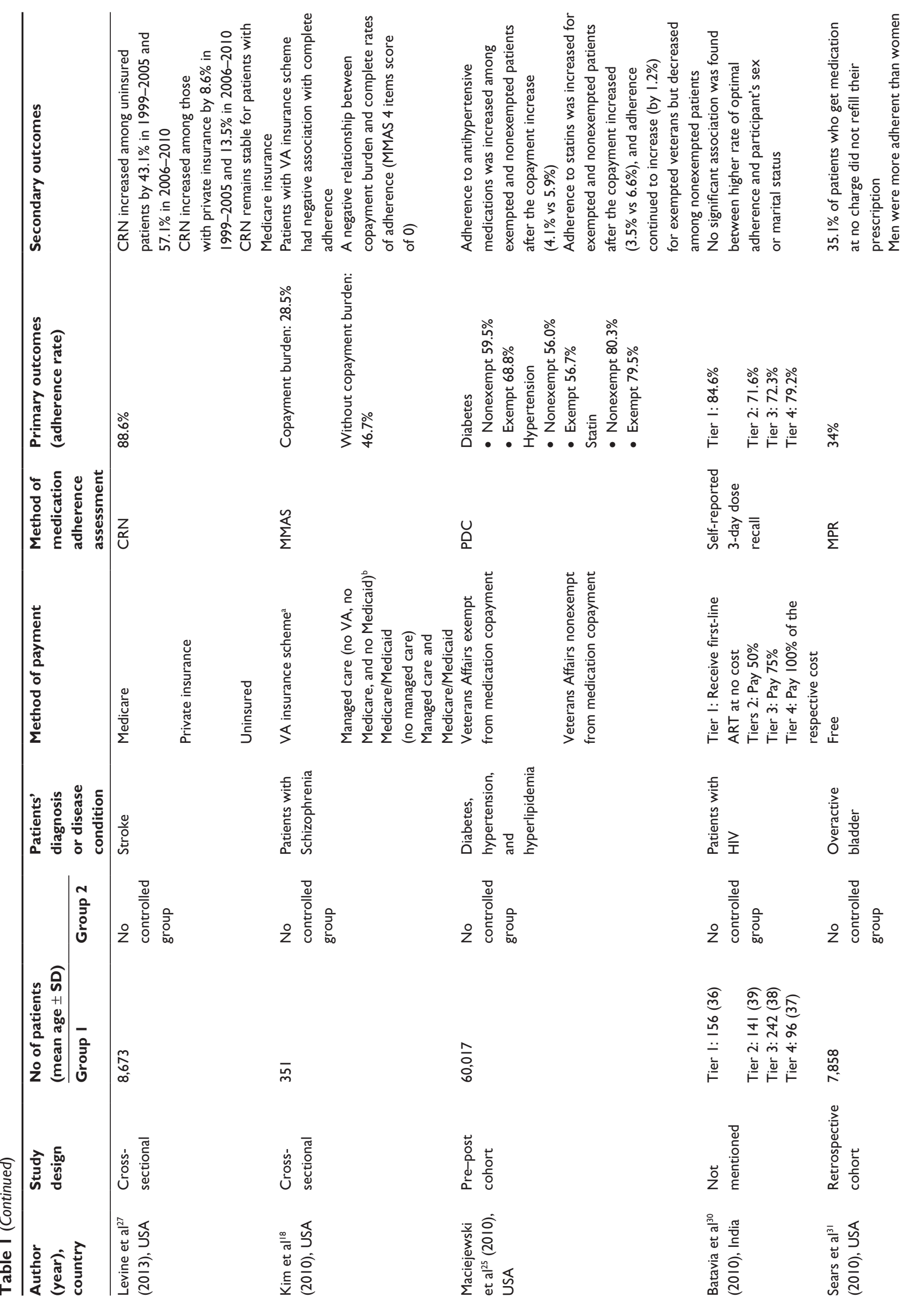



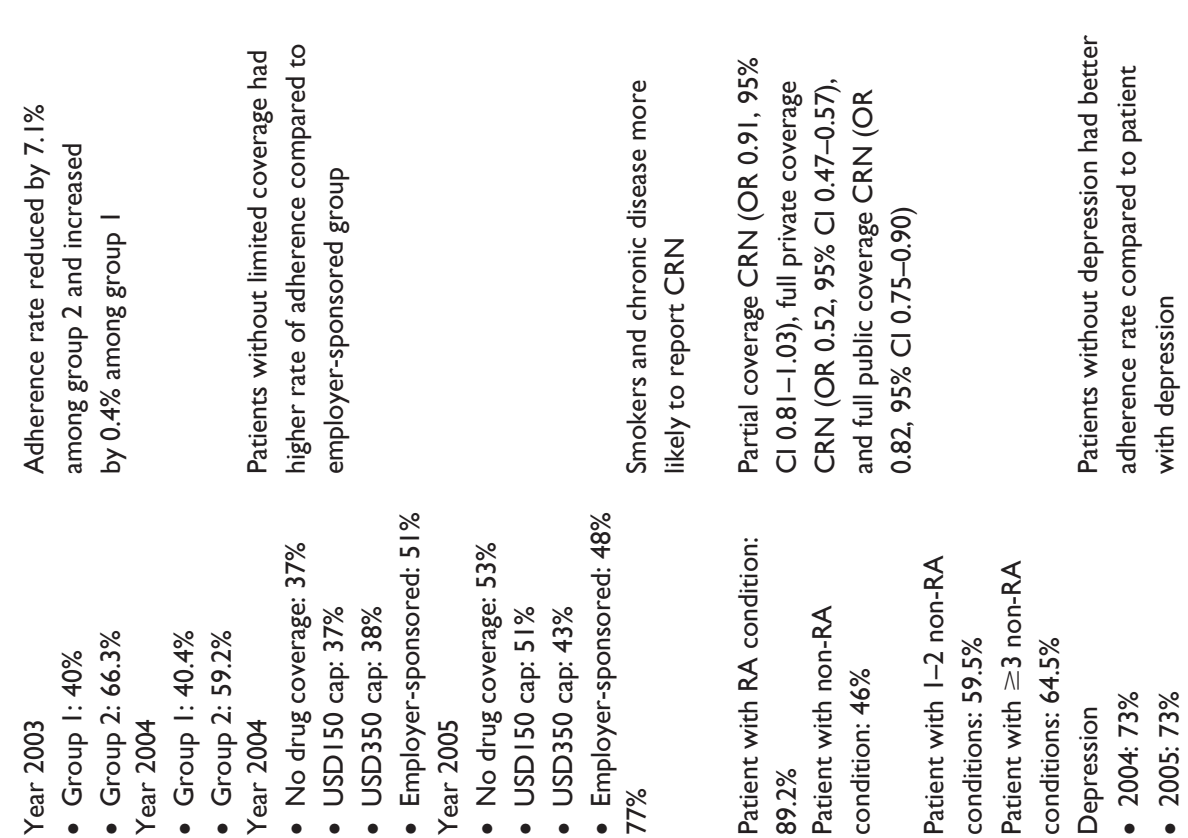

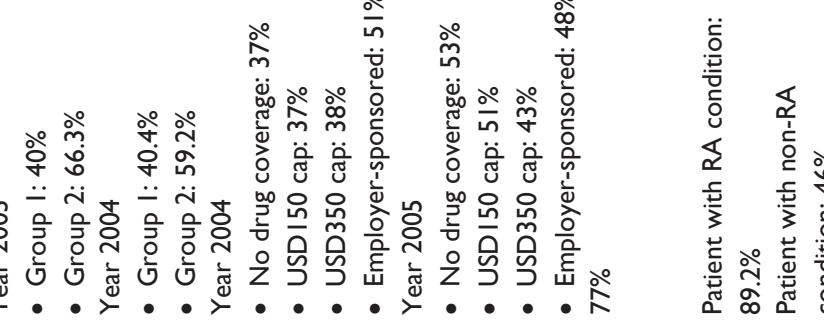

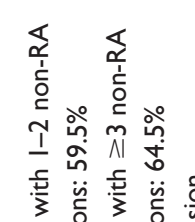

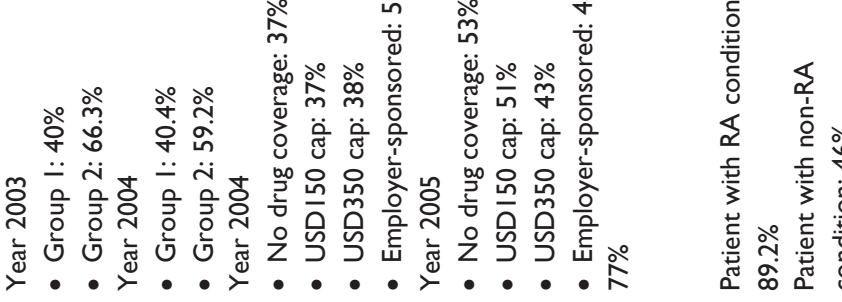

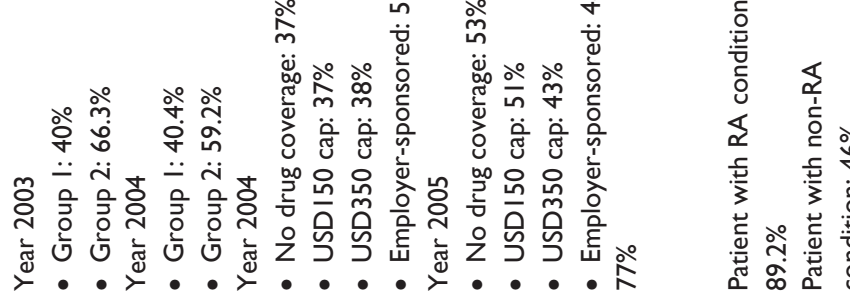

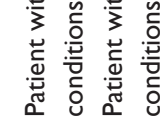

$\underset{\substack{\text { Un } \\ \text { Z }}}{Z}$

$\underset{\text { Z }}{\text { U }}$
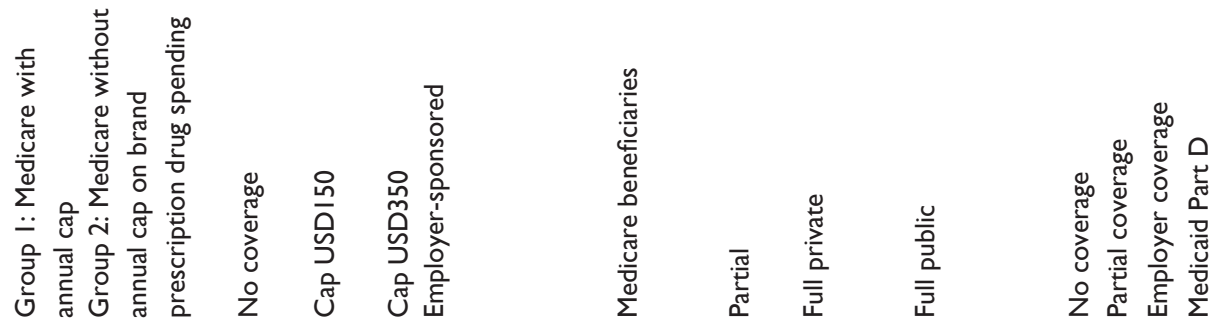

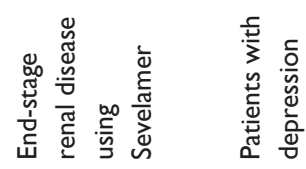
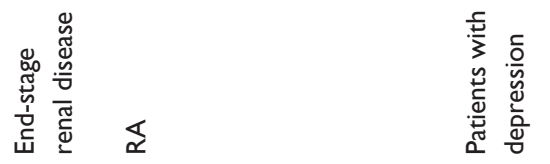

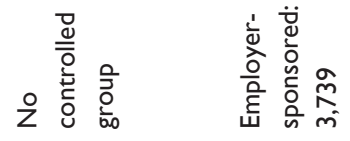

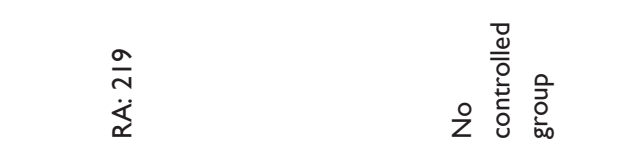

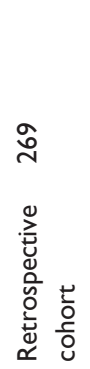

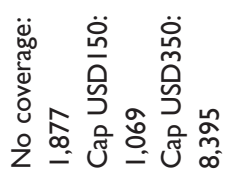

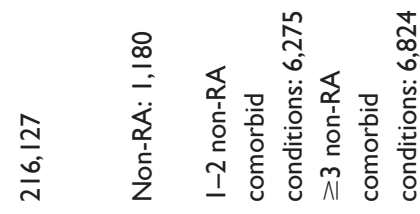

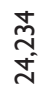

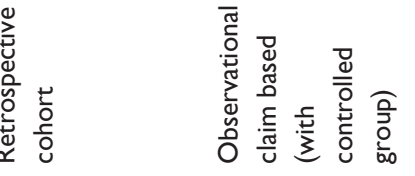

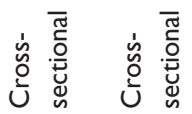

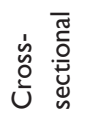

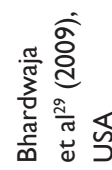

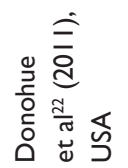

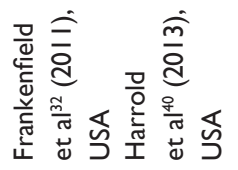

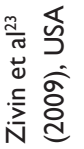

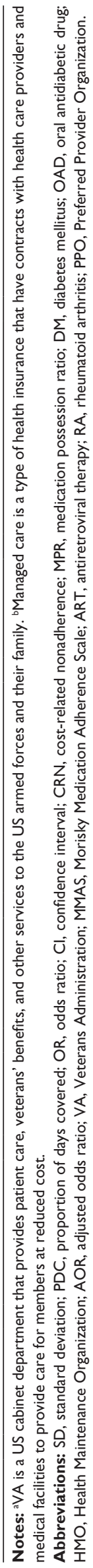


power of the studies. A summary of the quality assessment criteria used is provided in Table S1.

\section{Method of medication adherence measurement}

Of the 21 studies included, various methods were used to measure medication adherence rate. The most common medication adherence tool used to measure rate of adherence was $\mathrm{CRN}(\mathrm{n}=11)$. CRN measured medication adherence by using a validated survey which required a recall period of the last 12 months. The higher the score of CRN is, the poorer the medication adherence will be. Five studies used "proportion of days covered" that measures adherence through number of days covered by the prescription fills. Other studies used "medication possession ratios" (MPRs) $(\mathrm{n}=3)$, Morisky Medication Adherence Scale (MMAS) $(\mathrm{n}=1)$, and selfreport 3-day dose recall $(n=1)$. MPRs measure medication adherence through calculation of the percentage of time patient has access to medication prescribed. Meanwhile, the MMAS and 3-day dose recall are self-report of medicationtaking behavior.

\section{Payment schemes and their influence on medication adherence}

Our review found several methods of payments that may influence patients' adherence to medication. The methods of payments described were 1) copayment or out-ofpocket expenditure, 2) drug coverage or insurance benefits, 3) prescription benefit coverage limit or prescription cap, and 4) free or subsidized medication.

\section{Copayment or out-of-pocket expenditure}

Out-of-pocket expenditures were described as payments paid for coinsurance, copayments, or deductibles for medical-related items or services that were not covered by the insurance. ${ }^{13}$ Copayment refers to a fixed amount of payment (eg, USD10) made by patients for a covered health care service. The amount of copayment can vary depending on types of health care services used by patients. ${ }^{14}$

There were nine studies that reported the effects of medication copayment or out-of-pocket expenditure on patients' adherence to medications. In all the studies, high copayment or out-of-pocket expenditure for medication had significant association with medication nonadherence. ${ }^{9,15-22}$ The study by Aarnio et al found that poor adherence among new statin users was 1.3 times more likely to occur in patients with medication copayment than those who were not. ${ }^{17}$ The same study also reported that an increase of $€ 0.20$ copayment per statin tablet had caused a significant reduction of $36 \%$ in patients' adherence to medication. ${ }^{17}$ Similarly, other studies by Zivin et al, ${ }^{23}$ Castaldi et al,${ }^{16}$ Sedjo et al, ${ }^{21}$ Gibson et al, ${ }^{24}$ and Zheng et $\mathrm{al}^{9}$ also reported that the amount of out-of-pocket expenditure for medication influenced patients' adherence to medications. In these studies, patients who spent their out-of-pocket money of $>$ USD20-USD100 per month were more likely to have CRN than patients who spent $<\mathrm{USD} 10 .{ }^{21}$ Interestingly in the study by Kim et al, medication adherence of patients with schizophrenia was reported to be influenced by patients' perceptions of the burden of the medication copayment. ${ }^{18}$ The study revealed that the more patients perceived that medication copayment was a burden, the more nonadherent they would be ${ }^{18}$ Despite the positive associations between high medication copayment and medication nonadherence, one study reported that adherence to statin, antihypertensive medication, and oral hypoglycemic agents was increased after a rise of USD5 in medication copayment. ${ }^{24}$ The increment of medication adherence rate, however, was reported to decline after 11 months following the therapy, especially among veterans who need to pay for the copayment. ${ }^{25}$

\section{Drug coverage or insurance benefit}

There were four studies that reported association between drug coverage or insurance benefits and patients' adherence to medications. The drug coverage payment schemes used in these studies were Medicare Part D or Health Maintenance Organization. The Medicare Part D is a subsidized premium for prescription drug coverage provided by private insurance organizations. Patients who do have insurance benefit or drug coverage are required to pay the full medication cost themselves. The studies show that patients who did not have drug coverage were more nonadherent to their medication. ${ }^{9,24,26,27}$

Interestingly, medication adherence rate was found to increase by $12 \%$ among patients who later received insurance coverage (previously were not on insurance drug coverage). ${ }^{22}$ In the study, the reduction of cost-sharing by the patients and expanded drug coverage had enhanced patients' adherence to their medication. ${ }^{22}$ Similar results were also reported by Kennedy et al who reviewed medication adherence pattern among Medicare beneficiaries. In their study, patients who were newly insured had better reduction of CRN rate compared to patients who were continuously insured or uninsured. ${ }^{28}$ The results shows that $\mathrm{CRN}$ rate dropped by $7.8 \%$ when patients started to receive Medicare Part D coverage compared to patients who were continuously insured 
(CRN dropped only by 3.6\%) or continuously insured (CRN dropped by 3.1\%). ${ }^{28}$ However, among Medicare Part D beneficiaries, the adherence rate of patients aged 65 years and older was found to be lower than those who were not on medication drug coverage $(7.7 \%$ vs $4.5 \%, P=0.01) .{ }^{27}$

\section{Prescription benefit coverage limit or prescription cap}

In the current study, only two studies reported the influence of prescription drug cap on patients' adherence to medications. ${ }^{22,29}$ In these studies, the prescription benefit coverage limits or prescription cap requires patients to pay a certain amount of payment when prescription drug cap was exceeded. The study by Donohue et al found that the medication adherence rate among patients with depression was low in patients with lower prescription benefit coverage limits. However, when the same patients were enrolled in Medicare Part D which include an expansion of drug coverage that reduced patient's out-of-pocket expenditure, medication adherence was increased by $16 \%$ (odds ratio $1.86,95 \%$ confidence interval $1.44-2.39, \chi^{2}=22.97$, $P<0.0001) .{ }^{22}$ The second study by Bhardwaja et al on end-stage renal disease patients reported that higher medication adherence rate was found among patients without capped benefit than patients with capped benefit of brand prescription drug (patients need to pay the full cost of the medication when cap was reached). ${ }^{29}$ The reported adherence rate in 2004 was $66.3 \%$ among patients without capped benefit and $40 \%$ among patients with capped prescription benefit scheme. ${ }^{29}$

\section{Subsidized medications}

The influence of subsidized or no medications charge on patients' adherence was only reported in two studies. ${ }^{30,31}$ The study among patients with overactive bladder medications who were fully subsidized by the Military Health System, USA, found that patients had adequate adherence to their medications. ${ }^{31}$ In the study, the adherence rate was ninefold higher than previously reported study in which patients need to pay the medication cost themselves. ${ }^{31}$ Another study by Batavia et al on Graduated Cost Recovery program in India that evaluated the effect of free medication on patient's adherence divided patients into four groups according to the amount of financial assistance received by the patients. Depending on the patients' socioeconomic background, patients in Tier 1 received medication at no charge (had monthly income of USD38.30-USD74.70), and patients in Tier 2 (had monthly income of USD76.60-USD127.70),
Tier 3 (had monthly income of USD114.9-USD204.30), and Tier 4 (had monthly income of USD198-USD434.20) were required to pay $50 \%, 75 \%$, and $100 \%$ of their medication cost, respectively. ${ }^{30}$ The results of the study demonstrated that patients who received their medication in Tier 1 had adequate medication adherence $(84.6 \%$ of the patients took $95 \%$ or greater of all prescribed doses in 3 days before the study visit) than patients who need to pay their medication (only 71\%-79\% of patients in Tier 2-4 took their medication as prescribed). ${ }^{30}$ The study concluded that increment of financial assistance in medication cost was better associated with good medication adherence rate..$^{30}$

\section{Secondary outcomes}

The current study found that despite receiving drug coverage or paying out-of-pocket money, patients' adherence to medication decreased over time. ${ }^{17,25} \mathrm{~A}$ few studies reported that patients of younger age were more likely to be related to nonadherence to their medication compared to older patients. ${ }^{20,21,24,26,28}$ Nevertheless, in four studies, patients with multiple chronic conditions were found to be more likely to have CRN than patients without multiple chronic conditions. ${ }^{19-21,28,32}$ Nonadherence to medications was also reported to be influenced by low-income status of the patients ${ }^{19,20,26,33,34}$ and patients' perceptions of financial burden. ${ }^{18,19}$

\section{Discussion}

The current study reviewed the influence of medication payment schemes on patients' medication adherence. Of the 21 located studies, four medication payment schemes were reported to have significant association with patients' medication adherence rate. The payment schemes were copayment or out-of-pocket expenditure, drug coverage or insurance benefit, prescription benefit coverage limits or prescription cap, and free of charge or fully subsidized. Our review found that higher out-of-pocket expenditure or copayment borne by patients may influence patients' medication adherence depending on 1) the amount of out-of-pocket money spent for medications, 2) the perceived financial burden of medication, and 3) type of patients and diseases such as young-aged and chronic diseases.

The current study found that the limit of patients' copayment that potentially caused nonadherence to medication varied between USD20 and USD100. This may be due to the difficulties in socioeconomic background and the influence of perceived medication burden. ${ }^{18,19}$ The study by Zheng et al among senior patients of the Ontario Public 
Drug Benefit found that the low-income patients who pay a copayment of USD2 per prescription medication had a lower limit copayment-related nonadherence of USD20. The same study reported that patients with high income had a higher limit of copayment-related nonadherence of USD $100 .{ }^{9}$ This is possibly due to the perceived burden of medication copayment viewed by patients with low income. Consistent with the study by Kim et al on patients with depression, adherence to medication was reported to be influenced by patients' perceptions of burden of medication cost. Patients who perceived medication copayment as a burden may be less motivated to take their medication, and thus have a greater likelihood of forgetting their medication. ${ }^{18}$ However, none of the studies described the true meaning of burden from patients' perspective. It is not known if other factors such as household expenses, number of members in the family, and severity of the disease may contribute to the perceived cost burden viewed by patients.

Our review also found that patients' adherence to the medication may be affected even with a small increment in medication copayment, for example, an increase of $€ 0.20$ per statin tablet. ${ }^{17}$ In a meta-analysis study by Matsui, an increase in each dollar of medication copayment was reported to decrease the adherence rate by $0.4 \% .{ }^{35}$ The same study found a significant relationship between increase in patient cost-sharing and decrease in medication adherence. However, interestingly, medication adherence rate was reported to increase during the early increment of medication copayment. ${ }^{25}$ Adherence to medication may seem to improve at the beginning of medication copayment increment maybe because patients had to pile up their medication stock following the hike in medication price. ${ }^{25}$ However, a reducing trend in medication adherence rate was observed after 11 months of medication copayment increment. ${ }^{25}$

The reduction in medication adherence among patients with chronic disease over time could be due to the development of the "doughnut hole" situation. The doughnut hole is defined as a gap in prescription drug coverage, due to which patients have to use high out-of-pocket money to pay for their medications. ${ }^{27}$ The "doughnut hole" situation usually occurs as the disease progresses and/or as the result of an increase in medication cost. When the disease progresses, patients may require more medications, and medical care may exceed the patients' insurance health coverage. Nonadherence to medication is believed to occur more when patients reach this "doughnut hole" situation. ${ }^{36,37}$ Other reported factors that may influence this reduction of medication adherence over time are patient's belief about medication effectiveness and side effect. ${ }^{38}$
The current study found that patients with no insurance drug coverage, or high out-of-pocket medication expenditure, were more nonadherent to medication than patients with insurance coverage. It was reported that patients unable to cope with the high out-of-pocket medication cost may not fill their prescriptions, reduce the intake of medication, and bargain their medication's price..$^{39}$ Interestingly, medication adherence rate improved among patients with no initial insurance drug coverage but later received insurance coverage. ${ }^{27,28}$ The newly insured patients were also found to have better adherence to medication that those who were continuously insured or uninsured. ${ }^{28}$ The reason behind this is unclear. It is possible to assume that patients at the early stage of the insurance benefits may value their medications more than later when adherence was reduced.

Nevertheless, the current study found that regardless of whether patients receive medications at lower cost or free of charge, the adherence rate to medications is still poor. This is especially evident among patients with nonchronic diseases. In the study by Sears et al, among patients with overactive bladder who received their medications at no charge, a high percentage of patients, $66 \%$, were found to be nonadherent to their medication. ${ }^{31}$ However, the nonadherence rate was found to be lower, $16 \%$ among patients with more serious diseases such as HIV. ${ }^{30}$ Although reduction of cost-sharing by patients may improve their adherence to medication, the current study shows that patients who need not pay for their medication may also be nonadherent to their medication. The reason for nonadherence among patients without medication cost burden is unknown.

It is important that the findings of this study be carefully interpreted. This is because the reported studies may have measured medication adherence among patients who returned to refill their medications. The medication adherence may be reduced if its included the nonadherence due to patients not returning for their medication as they cannot afford to purchase or acquire it. Nevertheless, adherence to medication among subsidized patients may be seen as similar to patients with unsubsidized medication scheme as patients may value their medications less than those who paid the medication cost themselves. To better understand the complex relationship between payment scheme and medication nonadherence, more research in the area should be done. Research that can help to calculate the point at which the health care costs of medication nonadherence could be offset by medication subsidies will help better management of resources, for example, by the government or employers' benefit scheme. 
This review is subject to a few limitations. First, it relates to the facts that there was heterogeneity in the definition of adherence and measurement methods of medication adherence between the studies. For example, in some studies, medication adherence was evaluated objectively using MPR and proportion of days covered, while others used subjective assessment methods such as MMAS and CRN. Thus, it is difficult to make a direct comparison between the studies and make systemic conclusions. The comparison of medication adherence between different payment schemes within each medication assessment method was not done as only limited studies are available in each domain. Second, the variety of study designs and methodologies makes robust comparisons challenging across different studies. Those differences might explain the variation in the reported association between costs and medication adherence. Finally, only two studies that investigated medication adherence among patients with medication subsidies were found. Therefore, generalization of results to other populations should be done cautiously.

\section{Conclusion}

Our review found that high out-of-pocket expenditure and lack of or no prescription drug coverage are strongly associated with reduction of patients' adherence to medication. Although reduction in out-of-pocket medication expenditure may improve patients' adherence to medication, the nonadherence rate among patients who received medication at no cost was found to be high especially in nonsevere disease. Factors that may influence the nonadherence among subsidized patients were unknown. Future study is required to investigate factors that may influence nonadherence among patients without cost-sharing constraint.

\section{Acknowledgment}

This study was funded by Fundamental Research Grant Scheme from the Ministry of Higher Education Malaysia (FGRS/2/2013/SKK02/UKM/03/1), and HA is the receiver of Hadiah Latihan Persekutuan Ministry of Health.

\section{Disclosure}

The authors declare that they have no conflicts of interest to disclose in this work.

\section{References}

1. Delamater AM. Improving patient adherence. Clin Diabetes. 2006; 24(2):71-77.

2. Ho PM, Bryson CL, Rumsfeld JS. Medication adherence: its importance in cardiovascular outcomes. J Am Heart Assoc. 2009;119(23): 3028-3035.
3. Al-Qasem A, Smith F, Clifford S. Adherence to medication among chronic patients in Middle Eastern countries: review of studies. East Mediterr Heal J. 2011;17(4):356-363.

4. Ramli A, Ahmad NS, Paraidathathu T. Medication adherence among hypertensive patients of primary health clinics in Malaysia. Patient Prefer Adherence. 2012;6:613-622.

5. New England Healthcare Institute. Thinking Outside the Pillbox. A SystemWide Approach to Improving Patient Medication Adherence for Chronic Disease. 2009. Available at: http://www.nehi.net/writable/publication_ files/file/pa_issue_brief_final.pdf. Accessed December 27, 2015.

6. Mackey K, Parchman ML, Leykum LK, Lanham HJ, Noël PH, Zeber JE. Impact of the chronic care model on medication adherence when patients perceive cost as a barrier. Prim Care Diabetes. 2012;6(2):137-142.

7. Jensen GA, Li Y. Long-run health effects of cost-related non-adherence to prescribed medications among adults in late midlife. $J$ Pharm Heal Serv Res. 2012;3(2):85-93.

8. Heisler M, Langa KM, Eby EL, Fendrick AM, Kabeto MU, Piette JD. The health effects of restricting prescription medication use because of cost. Med Care. 2004;42(7):626-634.

9. Zheng B, Poulose A, Fulford M, Holbrook A. A pilot study on cost-related medication nonadherence in Ontario. J Popul Ther Clin Pharmacol. 2012;19(2):e239-e247.

10. Hassali MA, Supian A, Ibrahim MI, et al. The Characteristics of Drug Wastage at the Hospital, Tuanku Jaafar Seremban, Malaysia: A Descriptive Study. J Clin Diagnostic Res. 2012;6(5):787-790.

11. Salas M, Hughes D, Zuluaga A, Vardeva K, Lebmeier M. Costs of medication nonadherence in patients with diabetes mellitus: a systematic review and critical analysis of the literature. Int Soc Pharmacoecon Outcomes Res. 2009;12(6):915-922.

12. Downs SH, Black N. The feasibility of creating a checklist for the assessment of the methodological quality both of randomised and nonrandomised studies of health care interventions. Journal of Epidemiology and Community Health. 1998;52(6):377-384.

13. Paez KA, Zhao L, Hwang W. Rising out-of-pocket spending for chronic conditions: a ten-year trend. Health Aff. 2009;28(1):15-25.

14. Center on Budget and Policy Priority. Key Facts You Need to Know About: Cost-Sharing Reductions. 2014. Available at: http://www. healthreformbeyondthebasics.org/wp-content/uploads/2014/09/ KeyFacts-Cost-Sharing-Reductions_updated2014.pdf. Accessed December 27, 2015.

15. Dusetzina SB, Winn AN, Abel GA, Huskamp HA, Keating NL. Cost sharing and adherence to tyrosine kinase inhibitors for patients with chronic myeloid leukemia. J Clin Oncol. 2014;32(4):306-311.

16. Castaldi PJ, Rogers WH, Safran DG, Wilson IB. Inhaler costs and medication nonadherence. Chest. 2010;138(3):614-620.

17. Aarnio EJ, Martikainen JA, Helin-Salmivaara A, et al. Register-based predictors of adherence among new statin users in Finland. J Clin Lipidol. 2014;8(1):117-125.

18. Kim E, Gupta S, Bolge S, Chen CC, Whitehead R, Bates JA. Adherence and outcomes associated with copayment burden in schizophrenia: a cross-sectional survey. J Med Econ. 2010;13(2):185-192.

19. Ngo-Metzger Q, Sorkin DH, Billimek J, Greenfield S, Kaplan SH. The effects of financial pressures on adherence and glucose control among racial/ethnically diverse patients with diabetes. J Gen Intern Med. 2011; 27(4):432-437.

20. Zivin K, Ratliff S, Heisler MM, Langa KM, Piette JD. Factors influencing cost-related nonadherence to medication in older adults: a conceptually based approach. Value Heal. 2010;13(4):338-345.

21. Sedjo RL, Devine S. Predictors of non-adherence to aromatase inhibitors among commercially insured women with breast cancer. Breast Cancer Res Treat. 2011;125(1):191-200.

22. Donohue JM, Zhang Y, Aiju M, et al. Impact of Medicare Part D on antidepressant treatment, medication choice and adherence among older adults with depression. Am J Geriatr Psychiatry. 2011; 19(12):989-997.

23. Zivin K, Jeanne MM, Amy JG, Zhang F, Stephen BS. Cost-related medication nonadherence among beneficiaries with depression following Medicare Part D. Am J Geriatr Psychiatry. 2009;17(12):1068-1076. 
24. Gibson TB, Song X, Alemayehu B, et al. Cost sharing, adherence, and health outcomes in patients with diabetes. Am J Manag Care. 2010; 16(8):589-600.

25. Maciejewski ML, Bryson CL, Perkins M, et al. Increasing copayments and adherence to diabetes, hypertension, and hyperlipidemic medications. Am J Manag Care. 2010;16(1):20-34.

26. Law MR, Cheng L, Dhalla IA, Heard D, Morgan SG. The effect of cost on adherence to prescription medications in Canada. Can Med Assoc J. 2012;184(3):297-302.

27. Levine DA, Morgenstern LB, Langa KM, Piette JD, Rogers MA, Karve SJ. Recent trends in cost-related medication nonadherence among US stroke survivors. Ann Neurol. 2013;73(2):180-188.

28. Kennedy JJ, Maciejewski M, Liu D, Blodgett E. Cost-related nonadherence in the Medicare program: the impact of Part D. Med Care. 2011; 49(5):522-526.

29. Bhardwaja B, Carroll N, Korner E, Nair KV. Impact of prescription benefit coverage limits on sevelamer hydrochloride adherence for patients with ESRD. Am Heal Drug Benefits. 2009;2(6):242-250.

30. Batavia AS, Balaji K, Houle E, et al. Adherence to antiretroviral therapy in patients participating in a graduated cost recovery program at an HIV care center in South India. AIDS Behav. 2010;14(4):794-798.

31. Sears CL, Lewis C, Noel K, Albright TS, Fischer JR. Overactive bladder medication adherence when medication is free to patients. J Urol. 2010;183(3):1077-1081.

32. Frankenfield DL, Howell BL, Wei II, Anderson KK. Cost-related nonadherence to prescribed medication therapy among Medicare Part D beneficiaries with end-stage renal disease. AMJ Heal Pharm. 2011;68(14): 1339-1348.
33. Gibson TB, Mark TL, Mcguigan KA, Axelsen K, Wang S. The effects of prescription drug copayments on statin adherence. Am J Manag Care. 2006;12(9):509-517.

34. William J, Streers WN, Ettner EL, Mangione CM, Duru OK. Cost-related nonadherence by medication type among Medicare Part D beneficiaries with diabetes. Med Care. 2013;51(2):193-198.

35. Matsui D. Medication adherence issues in patients: focus on cost. Clin Audit. 2013;5(3):33-42.

36. Polinski JM, Shrank WH, Huskamp HA, Glynn RJ, Liberman JN, Schneeweiss S. Changes in drug utilization during a gap in insurance coverage: an examination of the medicare part d coverage gap. PLoS Med. 2011;8(8):e1001075.

37. Briesacher BA, Gurwitz JH, Soumerai SB. Patients at-risk for costrelated medication nonadherence: a review of the literature. Gen Intern Med. 2007;22(6):864-871.

38. Jin J, Sklar GE, Sen OVM, Li SC. Factors affecting therapeutic compliance: a review from the patient's perspective. Ther Clin Risk Manag. 2008; 4(1):269-286

39. Cox ER, Henderson RR. Prescription use behaviour among Medicare beneficiaries with capped prescription benefits. J Manag Care Pharm. 2002;8(5):360-364.

40. Harrold LR, Briessacher BA, Peterson D, et al. Cost-related medication nonadherence in older rheumatoid arthritis patients. J Rheumatol. 2013;40(2):1-14. 


\section{Supplementary material}

Table SI Downs and Black's checklist for measuring study quality (score by paper)

\begin{tabular}{|c|c|c|c|c|c|c|c|c|c|c|c|c|c|c|c|c|c|c|c|c|c|c|c|c|c|c|c|c|}
\hline \multirow[t]{2}{*}{ Author (year) } & \multicolumn{27}{|c|}{ Item } & \multirow[t]{2}{*}{ Total } \\
\hline & I & 2 & 3 & 4 & 5 & 6 & 7 & 8 & 9 & 10 & II & 12 & 13 & 14 & 15 & 16 & 17 & 18 & 19 & 20 & 21 & 22 & 23 & 24 & 25 & 26 & 27 & \\
\hline Aarnio et al' (20l4) & $\mathrm{I}$ & 1 & 1 & $\mathrm{I}$ & $\mathrm{I}$ & $\mathrm{I}$ & $\mathrm{I}$ & I & I & 0 & 1 & I & I & 0 & 0 & 1 & I & I & I & I & 1 & $\mathrm{I}$ & 0 & 0 & 0 & 1 & 0 & 20 \\
\hline Castaldi et $\mathrm{al}^{2}(2010)$ & I & 1 & 1 & I & I & 1 & I & I & 1 & 0 & I & I & I & 0 & 0 & I & I & I & I & I & I & I & 0 & 0 & 0 & I & 0 & 21 \\
\hline Sedjo et $\mathrm{al}^{3}$ (20I I) & I & 1 & I & I & I & 1 & I & I & I & 0 & I & I & I & 0 & 0 & I & I & I & I & 1 & I & I & 0 & 0 & 0 & I & 0 & 20 \\
\hline William et $\mathrm{al}^{4}(2013)$ & I & I & I & I & I & I & I & I & I & 0 & I & I & I & 0 & 0 & 1 & I & I & I & I & I & I & 0 & 0 & 0 & I & 0 & 20 \\
\hline Zivin et $\mathrm{al}^{5}$ (20l0) & 1 & 1 & I & I & I & I & I & I & 1 & I & I & I & I & 0 & 0 & I & I & I & I & I & I & I & 0 & 0 & I & 1 & 0 & 22 \\
\hline Zheng et $\mathrm{al}^{6}(20 \mathrm{l} 2)$ & I & I & I & I & I & I & I & I & I & 0 & 0 & 0 & 0 & 0 & 0 & I & I & I & I & I & I & I & 0 & 0 & 0 & I & 0 & 17 \\
\hline Dusetzina et $\mathrm{al}^{7}(20 \mid 4)$ & I & I & I & I & I & I & I & I & I & I & I & I & I & 0 & 0 & I & I & I & I & I & I & I & 0 & 0 & I & I & 0 & 22 \\
\hline Ngo-Metzger et $\mathrm{al}^{8}(20 \mathrm{II})$ & $\mathrm{I}$ & 1 & 1 & $\mathrm{I}$ & I & 1 & I & I & I & 1 & I & I & I & 0 & 0 & 1 & I & $\mathrm{I}$ & $\mathrm{I}$ & 1 & I & $\mathrm{I}$ & 0 & 0 & 1 & $\mathrm{I}$ & 0 & 22 \\
\hline Gibson et $\mathrm{al}^{9}(2010)$ & I & 1 & I & I & I & $\mathrm{I}$ & I & I & I & I & I & I & 1 & 0 & 0 & I & I & I & I & I & 1 & $\mathrm{I}$ & 0 & 0 & 1 & I & 0 & 23 \\
\hline Law et $\mathrm{al}^{10}(2012)$ & 1 & 1 & 1 & 0 & I & I & I & I & I & 0 & I & I & I & 0 & 0 & I & I & I & I & I & I & I & 0 & 0 & 1 & I & 0 & 20 \\
\hline Kennedy et al" (20II) & $\mathrm{I}$ & I & I & I & I & $\mathrm{I}$ & I & I & I & 0 & I & I & I & 0 & 0 & I & I & I & I & I & I & I & 0 & 0 & 1 & I & 0 & 22 \\
\hline Levine et $\mathrm{al}^{12}(2013)$ & I & I & I & I & I & I & I & I & I & 0 & I & I & I & 0 & 0 & I & I & I & I & I & I & I & 0 & 0 & I & I & 0 & 21 \\
\hline Kim et $\mathrm{al}^{13}(2010)$ & I & 1 & 1 & $\mathrm{I}$ & I & 1 & I & I & I & 1 & I & I & I & 0 & 0 & 1 & I & $\mathrm{I}$ & I & 1 & I & $\mathrm{I}$ & 0 & 0 & 1 & $\mathrm{I}$ & 0 & 22 \\
\hline Maciejewski et al ${ }^{14}(2010)$ & $\mathrm{I}$ & 1 & I & $\mathrm{I}$ & I & $\mathrm{I}$ & I & I & I & 0 & I & I & I & 0 & 0 & I & I & I & I & I & I & $\mathrm{I}$ & 0 & 0 & I & $\mathrm{I}$ & 0 & 21 \\
\hline Batavia et al ${ }^{15}(2010)$ & 1 & 1 & 0 & 1 & I & 1 & 0 & I & 1 & 0 & 1 & I & 1 & 0 & 0 & 1 & I & 1 & 1 & I & 1 & I & 0 & 0 & 0 & 1 & 0 & 18 \\
\hline Sears et al ${ }^{16}(2010)$ & $\mathrm{I}$ & I & I & $\mathrm{I}$ & $\mathrm{I}$ & $\mathrm{I}$ & I & I & I & I & I & I & I & 0 & 0 & I & I & I & I & I & I & I & 0 & 0 & 0 & I & 0 & 21 \\
\hline Bhardwaja et al ${ }^{17}$ (2009) & $\mathrm{I}$ & 1 & I & I & I & $\mathrm{I}$ & I & I & I & 0 & I & I & I & 0 & 0 & I & I & I & I & I & I & I & 0 & 0 & I & I & 0 & 21 \\
\hline Donohue et al ${ }^{18}(20 \mathrm{II})$ & $\mathrm{I}$ & 1 & I & $\mathrm{I}$ & $\mathrm{I}$ & $\mathrm{I}$ & I & I & I & 0 & 1 & I & I & 0 & 0 & 1 & I & I & 1 & I & I & I & 0 & 0 & I & I & 0 & 21 \\
\hline Frankenfield et $\mathrm{al}^{19}(20 \mathrm{II})$ & 1 & 1 & 0 & I & I & $\mathrm{I}$ & I & I & I & 0 & 1 & I & 1 & 0 & 0 & 1 & I & I & 1 & I & 1 & I & 0 & 0 & 0 & 1 & 0 & 20 \\
\hline Harrold et $\mathrm{al}^{20}(2013)$ & $\mathrm{I}$ & I & 0 & I & I & $\mathrm{I}$ & I & I & I & I & I & I & I & 0 & 0 & I & I & I & I & I & 1 & I & 0 & 0 & 0 & I & 0 & 21 \\
\hline Zivin et $\mathrm{al}^{21}$ (2009) & I & I & 0 & I & I & I & I & I & I & I & I & I & I & 0 & 0 & I & I & I & I & I & I & I & 0 & 0 & 0 & I & 0 & 21 \\
\hline
\end{tabular}

Notes: 0: No; I: Yes. Items I-10: assessed whether the information provided was sufficient to allow the reader to make an unbiased assessment of the finding of the study; items II-13: assessed external validity - which addressed the extent to which findings from the study could be generalized to the population from which the study subjects were derived; items 14-20: assessed potential bias - which addressed biases in the measurement of the intervention and the outcome; items 2I-26: assessed confounding which addressed bias in the selection of the study subjects; item 27: assessed the power of study - which attempted to assess whether the negative findings from a study could be due to chance.

\section{References}

1. Aarnio EJ, Martikainen JA, Helin-Salmivaara A, et al. Register-based predictors of adherence among new statin users in Finland. J Clin Lipidol. 2014;8(1):117-125.

2. Castaldi PJ, Rogers WH, Safran DG, Wilson IB. Inhaler costs and medication nonadherence. Chest. 2010;138(3):614-620.

3. Sedjo RL, Devine S. Predictors of non-adherence to aromatase inhibitors among commercially insured women with breast cancer. Breast Cancer Res Treat. 2011;125(1):191-200.

4. William J, Streers WN, Ettner EL, Mangione CM, Duru OK. Cost-related nonadherence by medication type among Medicare Part D beneficiaries with diabetes. Med Care. 2013;51(2):193-198.

5. Zivin K, Ratliff S, Heisler MM, Langa KM, Piette JD. Factors influencing cost-related nonadherence to medication in older adults: a conceptually based approach. Value Heal. 2010;13(4):338-345.

6. Zheng B, Poulose A, Fulford M, Holbrook A. A pilot study on cost-related medication nonadherence in Ontario. J Popul Ther Clin Pharmacol. 2012;19(2):e239-e247.

7. Dusetzina SB, Winn AN, Abel GA, Huskamp HA, Keating NL. Cost sharing and adherence to tyrosine kinase inhibitors for patients with chronic myeloid leukemia. J Clin Oncol. 2014;32(4):306-311.

8. Ngo-Metzger Q, Sorkin DH, Billimek J, Greenfield S, Kaplan SH. The effects of financial pressures on adherence and glucose control among $\mathrm{racial} / \mathrm{ethnically} \mathrm{diverse} \mathrm{patients} \mathrm{with} \mathrm{diabetes.} \mathrm{J} \mathrm{Gen} \mathrm{Intern} \mathrm{Med.} \mathrm{2011;}$ 27(4):432-437.

9. Gibson TB, Song X, Alemayehu B, et al. Cost sharing, adherence, and health outcomes in patients with diabetes. Am J Manag Care. 2010;16(8): 589-600.
10. Law MR, Cheng L, Dhalla IA, Heard D, Morgan SG. The effect of cost on adherence to prescription medications in Canada. Can Med Assoc J. 2012;184(3):297-302.

11. Kennedy JJ, Maciejewski M, Liu D, Blodgett E. Cost-Related nonadherence in the Medicare program: the impact of Part D. Med Care. 2011;49(5):522-526.

12. Levine DA, Morgenstern LB, Langa KM, Piette JD, Rogers MA, Karve SJ. Recent trends in cost-related medication nonadherence among US stroke survivors. Ann Neurol. 2013;73(2):180-188.

13. Kim E, Gupta S, Bolge S, Chen CC, Whitehead R, Bates JA. Adherence and outcomes associated with copayment burden in schizophrenia: a cross-sectional survey. J Med Econ. 2010;13(2):185-192.

14. Maciejewski ML, Bryson CL, Perkins M, et al. Increasing copayments and adherence to diabetes, hypertension, and hyperlipidemic medications. Am J Manag Care. 2010;16(1):20-34.

15. Batavia AS, Balaji K, Houle E, et al. Adherence to antiretroviral therapy in patients participating in a graduated cost recovery program at an HIV care center in South India. AIDS Behav. 2010;14(4):794-798.

16. Sears CL, Lewis C, Noel K, Albright TS, Fischer JR. Overactive bladder medication adherence when medication is free to patients. J Urol. 2010;183(3):1077-1081.

17. Bhardwaja B, Carroll N, Korner E, Nair KV. Impact of prescription benefit coverage limits on sevelamer hydrochloride adherence for patients with ESRD. Am Heal Drug Benefits. 2009;2(6):242-250.

18. Donohue JM, Zhang Y, Aiju M, et al. Impact of Medicare Part D on antidepressant treatment, medication choice and adherence among older adults with depression. Am J Geriatr Psychiatry. 2011;19(12): 989-997. 
19. Frankenfield DL, Howell BL, Wei II, Anderson KK. Cost-related nonadherence to prescribed medication therapy among Medicare Part D beneficiaries with end-stage renal disease. AM J Heal Pharm. 2011; 68(14):1339-1348.

20. Harrold LR, Briessacher BA, Peterson D, et al. Cost-related medication nonadherence in older rheumatoid arthritis patients. $J$ Rheumatol. 2013;40(2):1-14.
21. Zivin K, Jeanne MM, Amy JG, Zhang F, Stephen BS. Cost-related medication nonadherence among beneficiaries with depression following Medicare Part D. Am J Geriatr Psychiatry. 2009;17(12):1068-1076.

\section{Publish your work in this journal}

Patient Preference and Adherence is an international, peer-reviewed, open access journal that focuses on the growing importance of patient preference and adherence throughout the therapeutic continuum. Patient satisfaction, acceptability, quality of life, compliance, persistence and their role in developing new therapeutic modalities and compounds to optimize clinical outcomes for existing disease states are major areas of interest for the journal. This journal has been accepted for indexing on PubMed Central. The manuscript management system is completely online and includes a very quick and fair peer-review system, which is all easy to use. Visit http://www. dovepress.com/testimonials.php to read real quotes from published authors.

Submit your manuscript here: http://www.dovepress.com/patient-preference-and-adherence-journal 